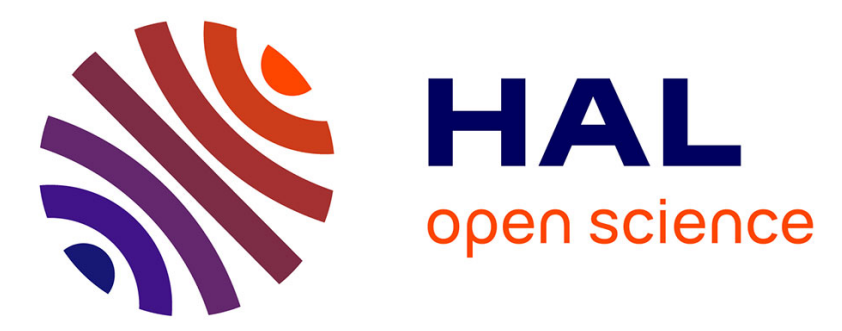

\title{
Reactions of antioxidants with molecular oxygen. Part II. \\ Isooctyl-3-(3,5-di-tert-butyl-4-hydroxyphenyl)propionate in silicone matrix
}

Rosa Navarro, Ludmila Audouin, Jacques Verdu

\section{To cite this version:}

Rosa Navarro, Ludmila Audouin, Jacques Verdu. Reactions of antioxidants with molecular oxygen. Part II. Isooctyl-3-(3,5-di-tert-butyl-4-hydroxyphenyl)propionate in silicone matrix. Polymer Degradation and Stability, 2011, 96 (5), pp.965-973. 10.1016/j.polymdegradstab.2011.01.024 . hal-02456020

\author{
HAL Id: hal-02456020 \\ https://hal.science/hal-02456020
}

Submitted on 27 Jan 2020

HAL is a multi-disciplinary open access archive for the deposit and dissemination of scientific research documents, whether they are published or not. The documents may come from teaching and research institutions in France or abroad, or from public or private research centers.
L'archive ouverte pluridisciplinaire $\mathbf{H A L}$, est destinée au dépôt et à la diffusion de documents scientifiques de niveau recherche, publiés ou non, émanant des établissements d'enseignement et de recherche français ou étrangers, des laboratoires publics ou privés. 


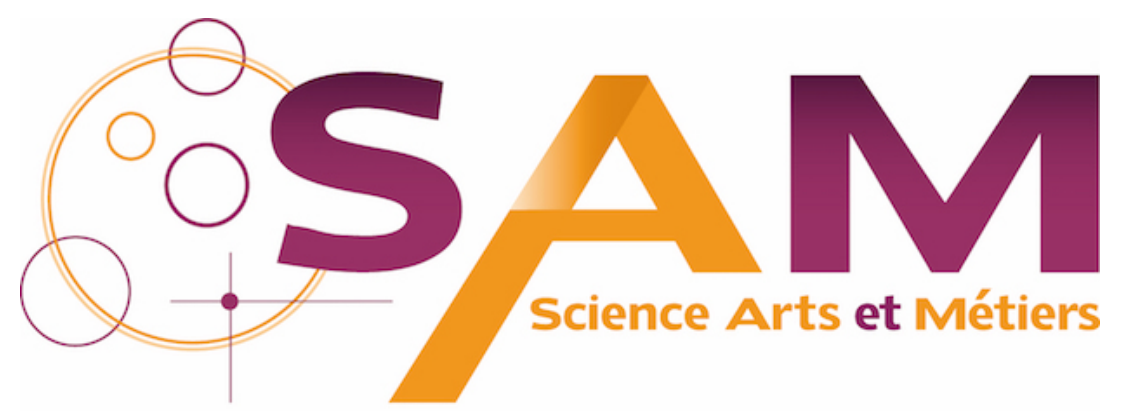

Archive Ouverte - Open Repository

\section{Science Arts \& Métiers (SAM)}

is an open access repository that collects the work of Arts et Métiers ParisTech researchers and makes it freely available over the web where possible.

This is an author-deposited version published in: https://sam.ensam.eu Handle ID: .http://hdl.handle.net/null

\section{To cite this version :}

R. NAVARRO, Ludmila AUDOUIN, Jacques VERDU - Reactions of antioxidants with molecular oxygen. Part II. Isooctyl-3-(3,5-di-tert-butyl-4-hydroxyphenyl)propionate in silicone matrix Polymer Degradation and Stability - Vol. Volume 96, Issue 5, p.Pages 965-973 - 2011 


\title{
Reactions of antioxidants with molecular oxygen. Part II. Isooctyl-3- (3,5-di-tert-butyl-4-hydroxyphenyl)propionate in silicone matrix
}

\author{
R. Navarro*, L. Audouin, J. Verdu \\ Arts et Métiers ParisTech, CNRS, PIMM, 151 boulevard de l'Hôpital, 75013 Paris, France
}

\begin{abstract}
A B S T R A C T
The study of oxidation kinetics of isooctyl-3-(3,5-di-tert-butyl-4-hydroxyphenyl)propionate (Irganox 1135) stabiliser was carried out using silicone oil as an inert substrate. The stabiliser was exposed at $80-120{ }^{\circ} \mathrm{C}$ under 0.02-3.0 MPa oxygen pressure. UV/VIS spectrophotometry, gel permeation chromatography and high pressure liquid chromatography were used to follow the stabiliser consumption, whose kinetic parameters were determined by applying a simple kinetic model.
\end{abstract}

Keywords:

Phenolic antioxidant

Thermal oxidation

Kinetics

UV/VIS

GPC

HPLC

\section{Introduction}

The reaction between hindered phenols used as polymer antioxidants and molecular oxygen was studied a long time ago [1-3]. In its ground state, oxygen is a biradical potentially able to abstract hydrogen from organic substrates. This reactivity is well known to specialists of high temperature gas phase oxidations, but it is slow in the temperature range of polymer use (typically $T \leq 200{ }^{\circ} \mathrm{C}$ ) and practically negligible in hydrocarbon polymers [4]. However, phenols are specially reactive owing to the low dissociation energy $\left(335-355 \mathrm{~kJ} \mathrm{~mol}^{-1}\right)$ of the $\mathrm{O}-\mathrm{H}$ bond $[5,6]$. The whole mechanism can be complex, but the first (and rate controlling) step is always the following:

$$
\mathrm{O}_{2}+\mathrm{Ph}-\mathrm{OH} \rightarrow \mathrm{HOO} \cdot \mathrm{Ph}-\mathrm{O} \cdot \quad\left(\mathrm{k}_{\mathrm{O}_{2}}\right)
$$

In air, at atmospheric pressure at $T \leq 150{ }^{\circ} \mathrm{C}$, this reaction is relatively slow which explains why it has been often ignored in papers on stabilisation mechanisms of hindered phenols $[7,8]$. However, there are circumstances in which there is no other way to explain the observed behaviour, than the hypothesis of a partial consumption of the stabiliser by its reaction with oxygen. The main characteristic feature of this behaviour is the kinetic curve of

\footnotetext{
* Corresponding author. Tel.: +331442463 07; fax: +33144246382.

E-mail addresses: rosa.navarro@paris.ensam.fr, rosa.navarro@ua.es (R. Navarro) ludmila.audouin@paris.ensam.fr (L. Audouin).
}

stabiliser consumption which displays its maximum rate at the beginning of exposure where the radical concentration is very low so that radical scavenging cannot significantly contribute to stabiliser consumption [4,9].

The rate of reaction (XI) is proportional to oxygen concentration in the polymer and this latter is proportional to oxygen pressure. In certain applications, for instance geotextiles [4], there is an interest in accelerated aging at low temperature $\left(\sim 80^{\circ} \mathrm{C}\right)$ and at high oxygen pressure. Indeed, in such conditions, oxygen-phenol reaction can be a non negligible mode of stabiliser consumption, responsible for a reduction of the stabiliser efficiency. This is a first reason to study oxygen-phenol reactions.

Another reason is that this study can bring some light to polymer stabilisation mechanisms. Molecular oxygen is, no doubt, less reactive than macroperoxy radicals formed during polymer oxidation, but the reaction product (phenoxy radical) and thus certain of its further by-products must be the same. Thus oxygenstabiliser reactions offer the possibility to study secondary stabilising processes without the analytical complications linked to polymer matrices. It has been shown in an earlier study [10] that silicone oil (polydimethylsiloxane) can be a convenient matrix for such experiments, provided that the stabiliser is soluble enough. Its main advantages are its total absence of UV absorption, inertness and compatibility with liquid chromatography.

Here, we have chosen to study a monofunctional phenol: isooctyl-3-(3,5-di-tert-butyl-4-hydroxyphenyl)propionate (Irganox 
a<smiles>Cc1cc(C(C)(C)C)c(O)c(C(C)(C)C)c1</smiles>

C<smiles>CCCCCCCc1cc(C(C)(C)C)c(O)c(C(C)(C)C)c1</smiles>

d<smiles>Cc1cc(CCC(=O)OCC(C)(C)C)cc(C(C)(C)C)c1O</smiles>

f

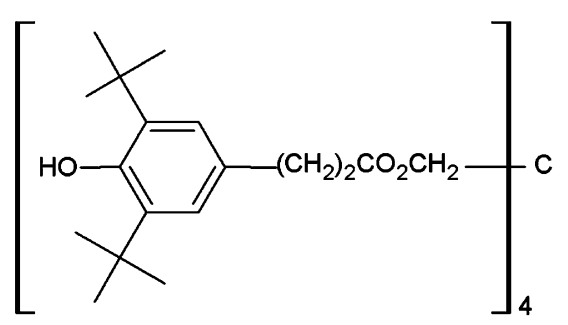

b<smiles>Cc1cc(Cc2cc(C)cc(C(C)(C)C)c2O)c(O)c(C(C)(C)C)c1</smiles>

Fig. 1. Structure of calibration compounds: (a) ionol, (b) Irganox 2246, (c) Irganox 1076, (d) Irganox 245, (e) Irganox 259 and (f) Irganox 1010.

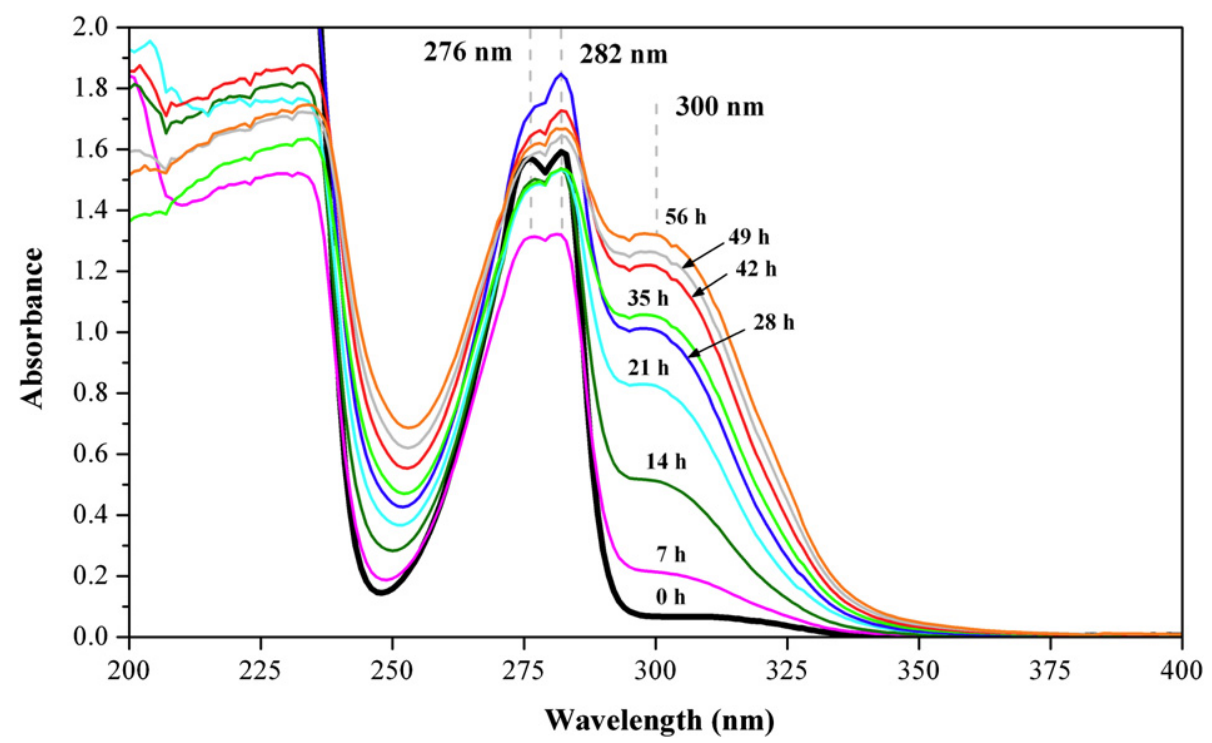

Fig. 2. Series UV/VIS spectra of the AO4 antioxidant after oxidation exposure at $90{ }^{\circ} \mathrm{C}$ under $3.0 \mathrm{MPa}$ oxygen pressure. 


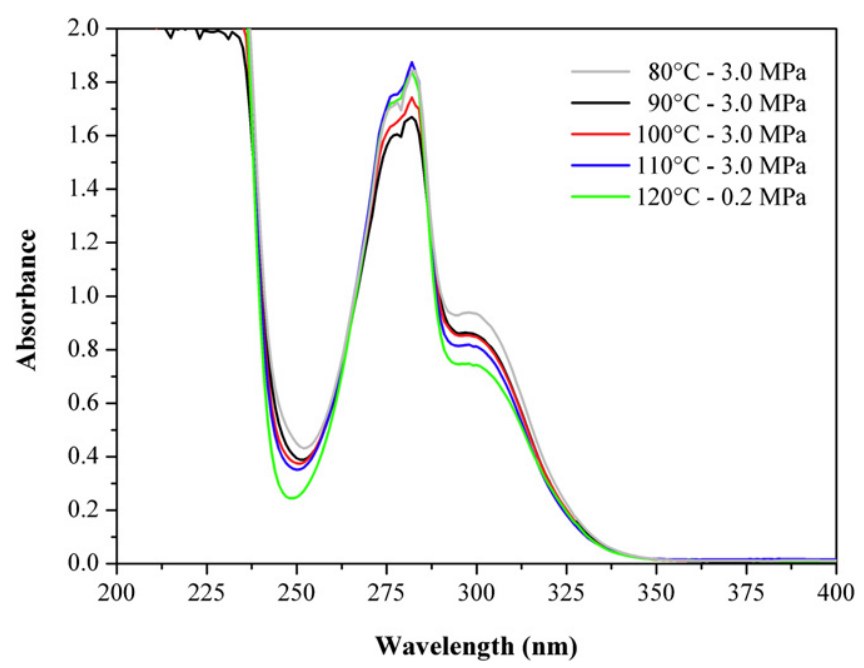

Fig. 3. UV/VIS spectra of AO4 after consuming $\sim 25 \%$ of initial stabiliser at different oxidation conditions.

1135), which is well soluble in silicone and belongs to an important antioxidant family characterized by the presence of a propionate ester grafted to the phenyl ring in the para position relative to the $\mathrm{OH}$ group. Reaction products obtained in the $80-120^{\circ} \mathrm{C}$ temperature range, $0.02-3.0 \mathrm{MPa}$ oxygen pressure range were studied by UV/VIS spectrophotometry, gel permeation chromatography and high pressure liquid chromatography.

\section{Equipment and experimental procedure}

\subsection{Materials}

The stabiliser used in this study was isooctyl-3-(3,5-di-tertbutyl-4-hydroxyphenyl)propionate (AO4) (commercial name Irganox 1135 from Ciba SC). This antioxidant has a molar mass of $390.6 \mathrm{~g} \mathrm{~mol}^{-1}$. Silicone oil DC 200 (viscosity $50 \mathrm{mPa}$ at $25^{\circ} \mathrm{C}$, from Sigma-Aldrich) was employed as an inert substrate.

\subsection{Oxidation conditions}

The phenolic stabiliser was dissolved in the polydimethylsiloxane to give $1.74 \times 10^{-2} \mathrm{~mol}^{-1}$ concentration $(0.68 \%$ weight). The oxidation of antioxidant solution was studied in an air-ventilated oven at $120^{\circ} \mathrm{C}$, and in autoclaves under $0.2-3.0 \mathrm{MPa}$ oxygen pressure range at $80,90,100,110$ and $120^{\circ} \mathrm{C}$. In the airventilated oven, the sample was introduced inside a closed container under air to prevent the evaporation of the antioxidant. The way to optimize these exposure conditions was presented in our previous article [10].

\subsection{Analytical methods}

The direct reaction between the stabiliser and the oxygen was followed by three different analytical methods: UV/VIS spectrophotometry, high pressure liquid chromatography (HPLC) and gel permeation chromatography (GPC).

Absorption spectra between the wavelengths of 200 and $500 \mathrm{~nm}$ were recorded in a Perkin-Elmer Lambda 35 UV/VIS spectrophotometer. Two cells of $500 \mu \mathrm{m}$ thickness were used to perform these measurements.

Both HPLC and GPC were carried out in a WATERS 714 chromatograph equipped with a photodiode array detector (PDA) and a differential refractometer. The PDA detector is an UV/VIS spectrophotometer which operates within a wavelength range of 190-800 $\mathrm{nm}$. The experimental conditions of chromatography varied according to the system used. In HPLC method, a symmetric C18 column $(5 \mu \mathrm{m}, 4.6 \times 150 \mathrm{~mm})$ was employed. The measurements were carried out under isothermal conditions at $40{ }^{\circ} \mathrm{C}$. The mobile phase consisted of acetonitrile at a flow rate of $1 \mathrm{ml} \mathrm{min}{ }^{-1}$. Several acetonitrile solutions of the phenol under study in known concentrations were prepared and analysed by HPLC in order to obtain a calibration curve. The amplitude of the chromatographic peak was found to be proportional to the phenol concentration. For antioxidant solutions in silicone oil, the following procedure was used: $2 \mathrm{ml}$ of acetonitrile were added to a known quantity ( $\sim 70 \mathrm{mg}$ ) of the silicone oil containing the phenol. The mixture was then vigorously stirred. After a brief rest period, both phases were separated and the acetonitrile phase was analysed by HPLC.

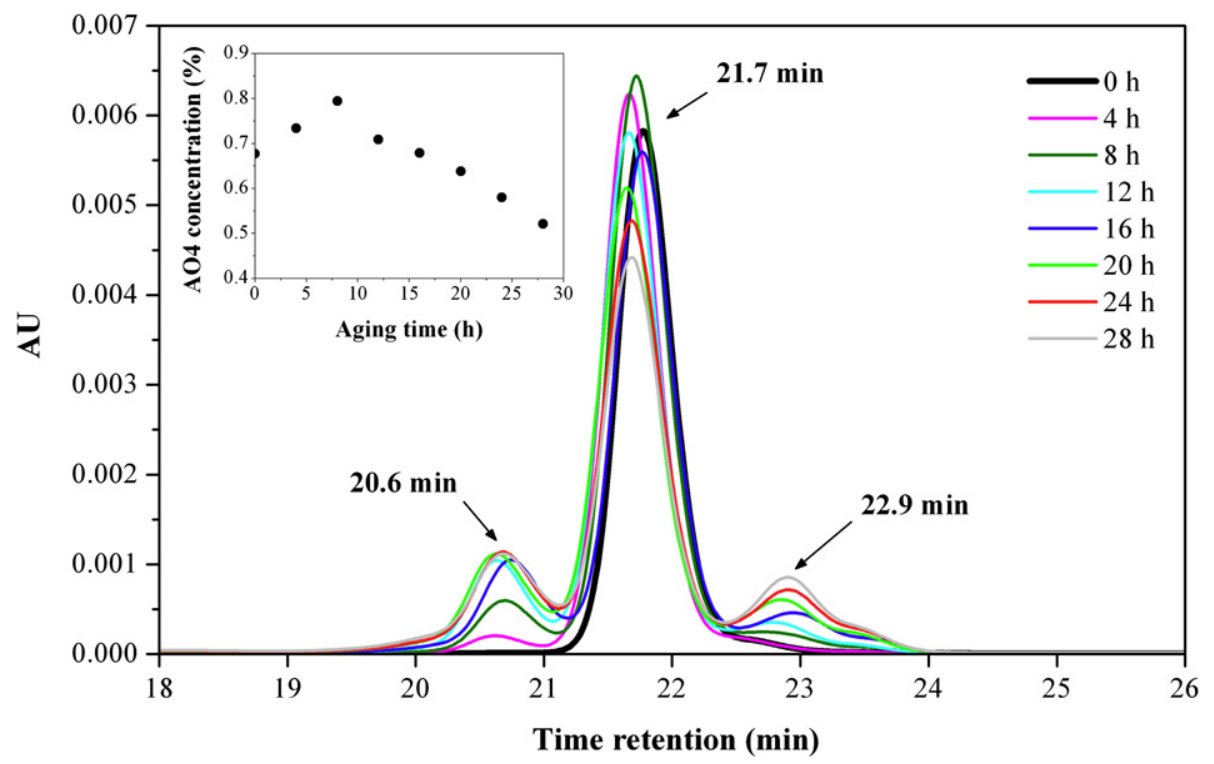

Fig. 4. Series GPC chromatograms of the $\mathrm{AO} 4$ antioxidant acquired at $276 \mathrm{~nm}$ after oxidation exposure at $110{ }^{\circ} \mathrm{C}$ under $3.0 \mathrm{MPa}$ oxygen pressure. 
From experiments made in virgin samples, it was shown that almost all the phenol initially present in silicone moved into acetonitrile. Although the phenol subsists, no doubt, in the silicone, it can be considered in a first approach that it is totally extracted, within experimental error, by acetonitrile. Since neither control samples of known concentration nor calibration curve were available for phenol by-products, chromatographic data relative to these species will not be quantitatively interpreted.

In GPC system, the temperature of column was maintained at $40^{\circ} \mathrm{C}$ too, but HR1 and HR4E columns $(5 \mu \mathrm{m}, 4.6 \times 300 \mathrm{~mm})$, placed in serial order, replaced the previous C18 column. This system enabled us to cover an effective molecular weight range from 50 to $100,000 \mathrm{~g} \mathrm{~mol}^{-1}$. Tetrahydrofuran (THF) was used as mobile phase at $0.3 \mathrm{ml} \mathrm{min}^{-1}$ flow rate. The molar mass calibration curve was obtained with different phenolic and aromatic compounds: toluene, xylene, ionol, Irganox 2246 (2,2'-methylene-bis(4-methyl6-tert-butylphenol)), Irganox 1076 (octadecyl-3-(3,5-di-tert-butyl4-hydroxyphenyl)-propionate), Irganox 245 (ethylenebis(oxyethylene)-bis(3-(5-tert-butyl-4-hydroxy-m-tolyl)-propionate)), Irganox 259 (1,6-hexamethylene-bis(3,5-di-tert-butyl-4-hydroxyhydrocinnamate)) and Irganox 1010 (pentaerythritol tetrakis(3-(3,5-di-tertbutyl-4-hydroxyphenyl)propionate)). The compound structures are shown in Fig. 1.

\section{Results and discussion}

\subsection{UV/VIS analysis}

The UV/VIS spectrum of the unreacted stabiliser displays a sharp doublet at 276 and $282 \mathrm{~nm}$, as it can be seen in Fig. 2. The $276 \mathrm{~nm}$
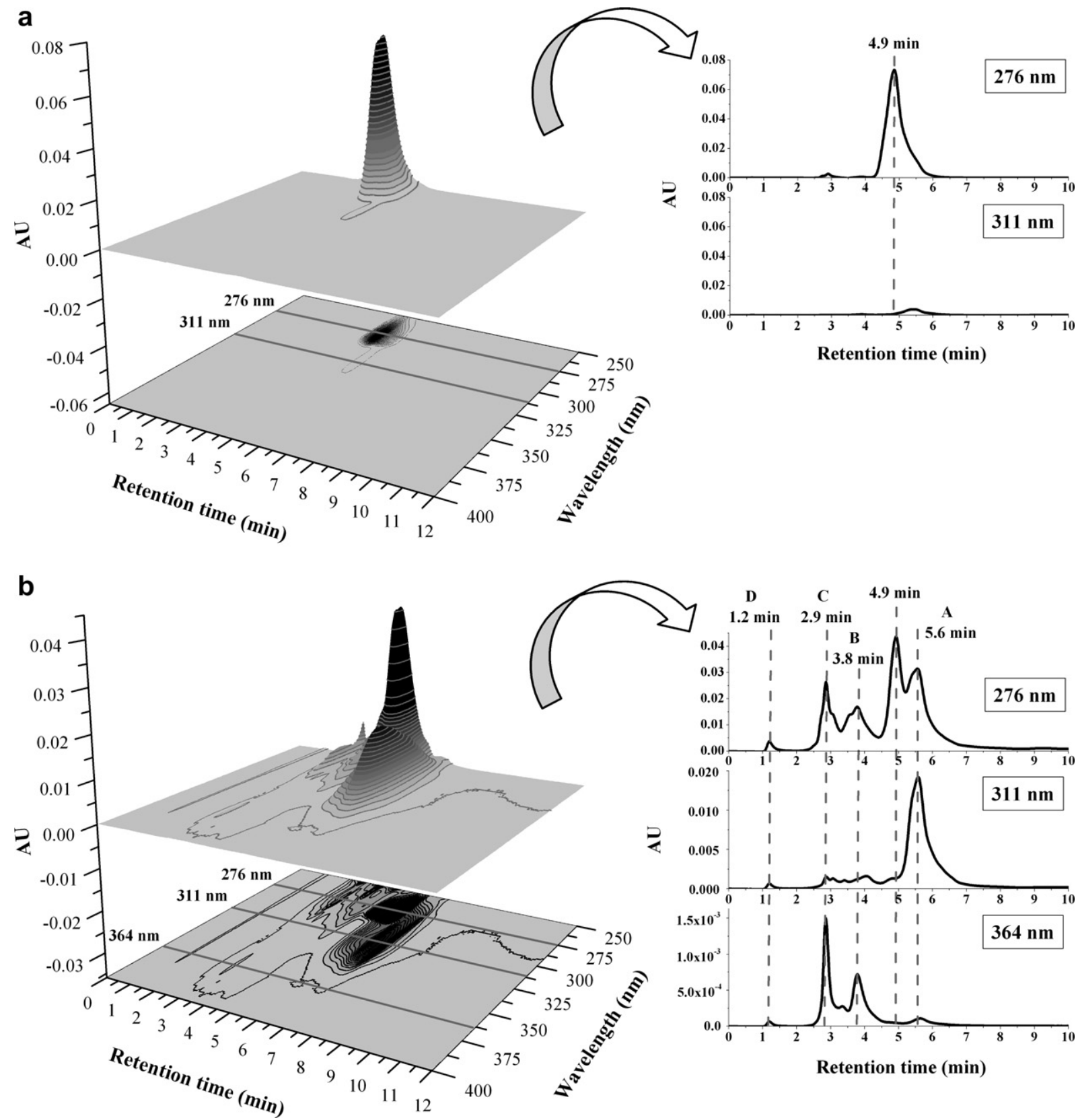

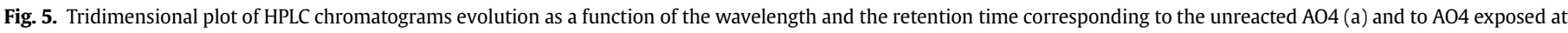
$110{ }^{\circ} \mathrm{C}$ under 3.0 MPa oxygen pressure during $28 \mathrm{~h}$ (b). 


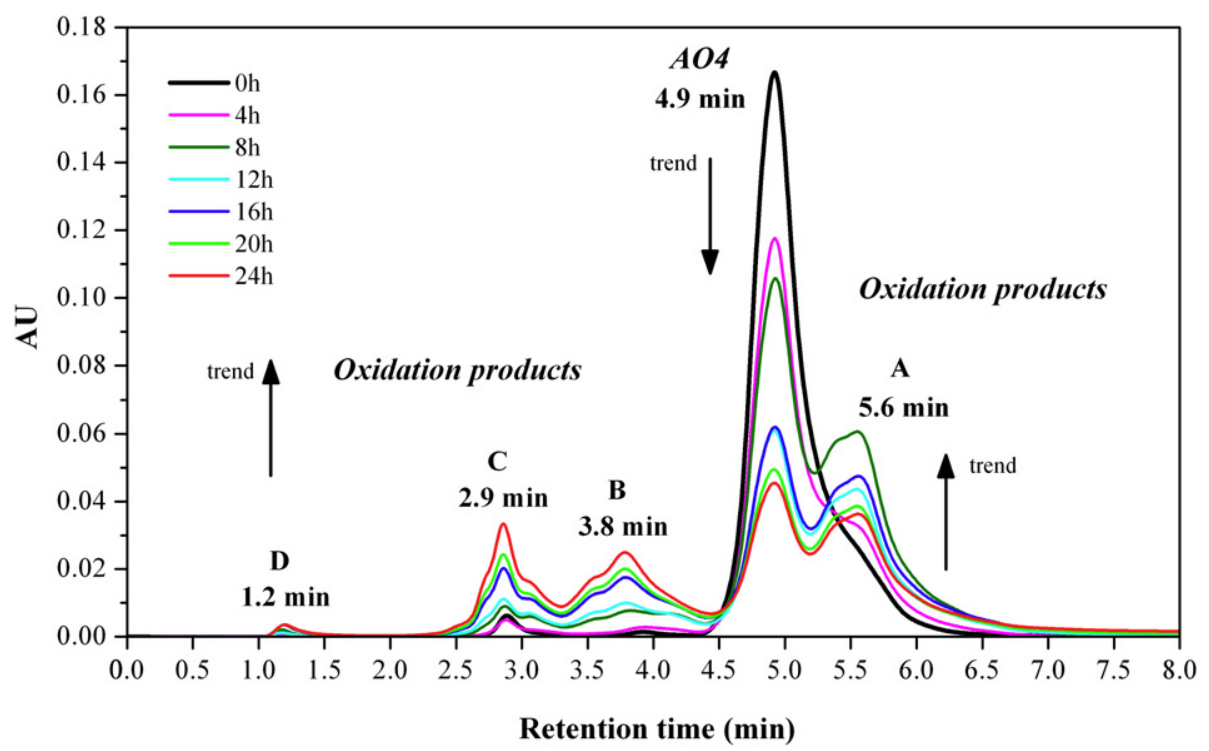

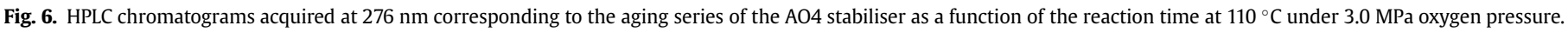

component has been chosen to focus on the kinetic analysis since it is less influenced by the growth of oxidation products absorbing at higher wavelength. Standards with different concentrations of the antioxidant in silicone oil were prepared to determine the molar absorptivity. In the case of AO4, the value of the molar absorptivity was $1742 \mathrm{l} \mathrm{mol}^{-1} \mathrm{~cm}^{-1}$. The unreacted stabiliser absorbs slightly at 300-330 $\mathrm{nm}$ range.

Fig. 2 shows the changes of UV/VIS spectra of the AO4 solution with exposure time at $90^{\circ} \mathrm{C}$ under $3.0 \mathrm{MPa}$ oxygen pressure. The stabiliser doublet is progressively overlapped by a wide band covering the whole $240-350 \mathrm{~nm}$ interval. This band displays a maximum at about $300 \mathrm{~nm}$. Other eventual maxima are masked by overlapping with residual stabiliser bands. The same behaviour was observed in the other experimental conditions under study. This band overlapping hinders the monitoring of the antioxidant consumption and, therefore, a kinetic analysis is impossible using this analytical technique. Despite the complexity of spectra in the oxidation process, according to UV/VIS analysis, one could say that apparently the same products are formed in the all studied experimental conditions. This is confirmed in Fig. 3, where spectra obtained after nearly $\sim 25 \%$ consumption of the initial antioxidant in various conditions are shown.

\subsection{GPC analysis}

Fig. 4 presents the chromatograms acquired with the UV detector at $276 \mathrm{~nm}$ after the exposure of the AO4 antioxidant to oxygen at $110^{\circ} \mathrm{C}$ under $3.0 \mathrm{MPa}$ oxygen pressure, as an example of evolution of GPC chromatograms obtained for this antioxidant. The chromatogram of the unreacted stabiliser displays a single peak at $21.7 \mathrm{~min}$, revealing the relative purity of AO4. Oxidation induces the growth of two relatively wide bands respectively centred at $22.9 \mathrm{~min}$ and $20.6 \mathrm{~min}$, but extending to $24 \mathrm{~min}$ on one side and 19 min on the other side. According to the molar mass calibration, the band maxima would correspond to $\sim 224 \mathrm{~g} \mathrm{~mol}^{-1}$ (22.9 min)

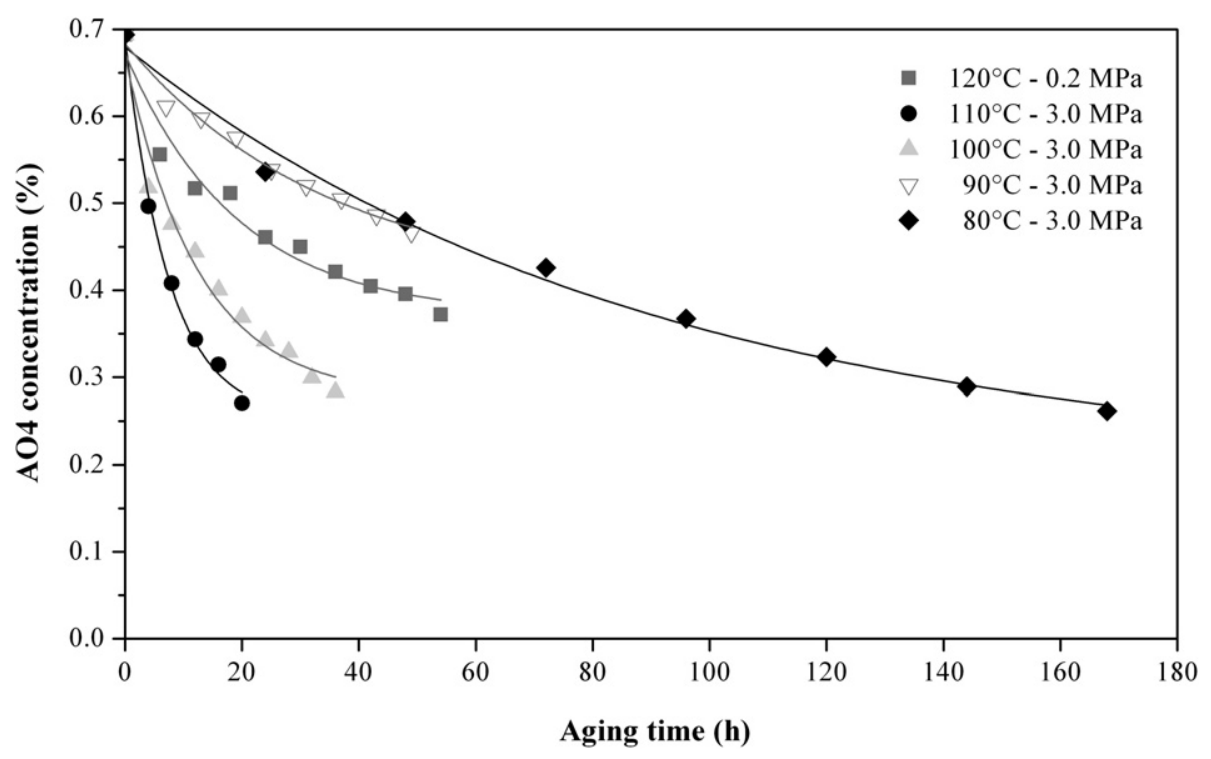

Fig. 7. The consumption curves of the AO4 stabiliser obtained by HPLC analysis at different experimental conditions. 
Table 1

Oxygen solubility values calculated in the silicone oil applying Clausius-Clapeyron law.

\begin{tabular}{|c|c|c|c|c|c|c|}
\hline \multirow[t]{2}{*}{$\mathrm{T}-\mathrm{P}_{\text {Oxygen }}$} & $80^{\circ} \mathrm{C}$ & $90{ }^{\circ} \mathrm{C}$ & $100{ }^{\circ} \mathrm{C}$ & $110^{\circ} \mathrm{C}$ & $120^{\circ} \mathrm{C}$ & $120^{\circ} \mathrm{C}$ \\
\hline & $3.0 \mathrm{MPa}$ & 3.0 MPa & $3.0 \mathrm{MPa}$ & $3.0 \mathrm{MPa}$ & $0.02 \mathrm{MPa}$ & $0.2 \mathrm{MPa}$ \\
\hline $\mathrm{S}_{\mathrm{O}_{2}}\left(\mathrm{~mol} \mathrm{l}^{-1} \mathrm{~Pa}^{-1}\right) \times 10^{8}$ & 5.00 & 4.92 & 4.85 & 4.78 & 4.71 & 4.72 \\
\hline
\end{tabular}

and $\sim 673 \mathrm{~g} \mathrm{~mol}^{-1}$ (20.6 min), but the molar mass range would extend from $\sim 132 \mathrm{~g} \mathrm{~mol}^{-1}$ to $\sim 1447 \mathrm{~g} \mathrm{~mol}^{-1}$.

Both bands of oxidation products increase continuously. Surprisingly, the peak relative to the unreacted stabiliser first increases slightly and then decreases. The simplest explanation of this behaviour is that a by-product having almost the same molar mass as AO4 but with a higher UV absorption "interferes" with AO4 but is more or less rapidly destroyed. This "interference" is not very favourable to the use of GPC for a kinetic study of stabiliser consumption.

\subsection{HPLC analysis}

The HPLC technique was used to achieve the complete separation between the starting antioxidant and its by-products. Fig. 5 shows the 3D chromatograms of the stabiliser before (a) and after exposure at $110{ }^{\circ} \mathrm{C}$ under 3.0 MPa oxygen pressure for $28 \mathrm{~h}$ (b). Fig. 5 (a) reveals the presence of two small satellites at retention times respectively close to 3.0 and $4.0 \mathrm{~min}$ and a shoulder close to $5.5 \mathrm{~min}$. These three species correspond to the major oxidation products as it is showed in Fig. 5 (b). In other words the stabiliser is initially slightly oxidized, that is not very surprising. Fig. 5 (b) reveals the presence of several by-products in addition to the three aforementioned ones. All these products absorb at $276 \mathrm{~nm}$, but they differ from the initial stabiliser by the following features:

- The by-product A having a retention time close to $5.5 \mathrm{~min}$ absorbs strongly at $311 \mathrm{~nm}$ but not at $364 \mathrm{~nm}$.

- The by-products $\mathrm{B}$ and $\mathrm{C}$ having retention times at respectively 3.8 and $2.9 \mathrm{~min}$ absorb at $364 \mathrm{~nm}$ but not at $311 \mathrm{~nm}$.

- The by-product $\mathrm{D}$ having the lowest retention time at $1.2 \mathrm{~min}$, absorbs at 276, 311 and $364 \mathrm{~nm}$.

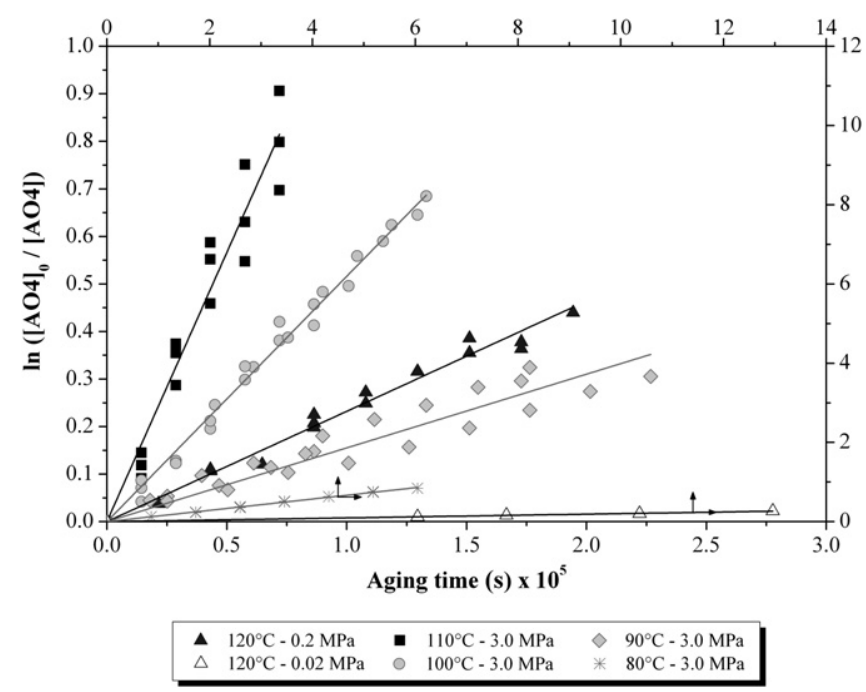

Fig. 8. Obtaining of the pseudo first order constant in different experimental conditions.
UV detection at $276 \mathrm{~nm}$ is characteristic for phenolic group absorption and $311 \mathrm{~nm}$ for quinone methide structures [11,12]. It is reasonable to suppose that, with this method, the separation is complete and a kinetic study of stabiliser consumption is possible. The study of the growth of by-products is expected to bring interesting complementary information.

Using a single wavelength detection at $276 \mathrm{~nm}$, we have monitored the changes of the HPLC chromatogram in the case of exposure at $110{ }^{\circ} \mathrm{C}$ under 3.0 MPa oxygen pressure (Fig. 6). Here, it can be observed that the peak at $4.9 \mathrm{~min}$, corresponding to the starting $\mathrm{AO} 4$ molecule, disappears almost completely, that confirms the absence (at least at moderate conversions, typically lower than 50\%) of any interference with by-products.

Kinetic curves of the AO4 stabiliser consumption obtained at different experimental conditions are presented in Fig. 7. In all the cases, the kinetic curves seem to correspond to a simple apparent first order process. The same behaviour was found with other phenolic stabilisers in thermal oxidation processes where the oxygen concentration was maintained constant $[9,10,13]$. As it was seen in a previous study made with $2,2^{\prime}$-methylene-bis(4-methyl6-tert-butylphenol) antioxidant [10], the true second order rate constant $\left(k_{\mathrm{O}_{2}}\right)$ can be estimated graphically from the stabiliser consumption rate using the following equations:

$\mathrm{AO} 4+\mathrm{O}_{2} \rightarrow$ oxidation products

$r_{\mathrm{AO} 4}=r_{\mathrm{O}_{2}}=-f_{\mathrm{AO}} k_{\mathrm{O}_{2}}\left[\mathrm{O}_{2}\right][\mathrm{AO} 4]$

where $f_{\mathrm{AO} 4}$ is the phenol functionality $\left(f_{\mathrm{AO} 4}=1\right.$ for $\left.\mathrm{AO} 4\right),\left[\mathrm{O}_{2}\right]$ and [AO4] are the respective oxygen and residual stabiliser concentrations in the silicone oil solution. If $\left[\mathrm{O}_{2}\right]$ is considered constant, the system behaves as a pseudo first order process. Therefore,

$K=k_{\mathrm{O}_{2}}\left[\mathrm{O}_{2}\right]$

$\frac{\mathrm{d}[\mathrm{AO} 4]}{\mathrm{d} t}=-K[\mathrm{AO} 4]$

The integration leads to:

$[\mathrm{AO} 4]=[\mathrm{AO} 4]_{0} e^{-K t}$

where $K$ is the pseudo first order constant and $\left[\mathrm{O}_{2}\right]=\mathrm{S}_{\mathrm{O}_{2}} \cdot \mathrm{P}_{\mathrm{O}_{2}}, \mathrm{~S}_{\mathrm{O}_{2}}$ being the oxygen solubility in the silicone oil $\left(\mathrm{mol} \mathrm{l}^{-1} \mathrm{~Pa}^{-1}\right)$, and $\mathrm{P}_{\mathrm{O}_{2}}$ the oxygen pressure ( $\mathrm{Pa}$ ). The temperature dependence of the solubility was taken into account through the Clausius-Clapeyron law [14] (Table 1).

First order plots are shown in Fig. 8. In all the conditions under study they are straight lines passing through the origin, as theoretically expected. The first order constants $K$ can be obtained from the slopes and the true second order rate constants are obtained by dividing $K$ by the oxygen concentration. These data are compiled in Table 2 . The true second order rate constant is independent of oxygen pressure, as expected and illustrated by the results obtained at $120^{\circ} \mathrm{C}$ for 0.02 and $0.2 \mathrm{MPa}$ oxygen pressures. At $80{ }^{\circ} \mathrm{C},\left(k_{\mathrm{O}_{2}}\right)=9.4 \times 10^{-6} 1 \mathrm{~mol}^{-1} \mathrm{~s}^{-1}$ while, at the same temperature but in different experimental conditions, it was found $k_{\mathrm{O}_{2}}=3.5 \times 10^{-6} 1 \mathrm{~mol}^{-1} \mathrm{~s}^{-1}$ for Irganox 1010, a stabiliser belonging to the same family [4]. These values can be considered relatively close owing to the diversity of error sources. These authors [4] obtained this value at $80{ }^{\circ} \mathrm{C}-5.0 \mathrm{MPa}$ and using infrared technique to measure the antioxidant concentration.

The values of $k_{\mathrm{O}_{2}}$ were put in an Arrhenius plot together with Irganox 1010 one in Fig. 9. The points are not very far from a straight-line of which the parameters allow us to determine the pre-exponential factor $k_{\mathrm{O}_{2} \mathrm{O}} \approx 1.9 \times 10^{9} \mathrm{1} \mathrm{mol}^{-1} \mathrm{~s}^{-1}$ and the activation energy $E_{\mathrm{act}} \approx 98 \mathrm{~kJ} \mathrm{~mol}^{-1}$. 
Table 2

Kinetic parameters corresponding to the direct reaction of the AO4 antioxidant with oxygen.

\begin{tabular}{|c|c|c|c|c|c|c|}
\hline \multirow[t]{2}{*}{$\mathrm{T}-\mathrm{P}_{\text {Oxygen }}$} & $80^{\circ} \mathrm{C}$ & $90{ }^{\circ} \mathrm{C}$ & $100{ }^{\circ} \mathrm{C}$ & $110^{\circ} \mathrm{C}$ & $120^{\circ} \mathrm{C}$ & $120^{\circ} \mathrm{C}$ \\
\hline & 3.0 MPa & $3.0 \mathrm{MPa}$ & 3.0 MPa & $3.0 \mathrm{MPa}$ & $0.02 \mathrm{MPa}$ & $0.2 \mathrm{MPa}$ \\
\hline$K\left(\mathrm{~s}^{-1}\right) \times 10^{6}$ & $1.43 \pm 0.01$ & $1.55 \pm 0.27$ & $5.16 \pm 0.11$ & $11.32 \pm 1.61$ & $0.20 \pm 0.03$ & $2.32 \pm 0.15$ \\
\hline$k_{\mathrm{O}_{2}}\left(1 \mathrm{~mol}^{-1} \mathrm{~s}^{-1}\right) \times 10^{5}$ & $0.94 \pm 0.01$ & $1.04 \pm 0.18$ & $3.50 \pm 0.07$ & $7.79 \pm 1.11$ & $21.24 \pm 3.78$ & $24.28 \pm 1.57$ \\
\hline
\end{tabular}

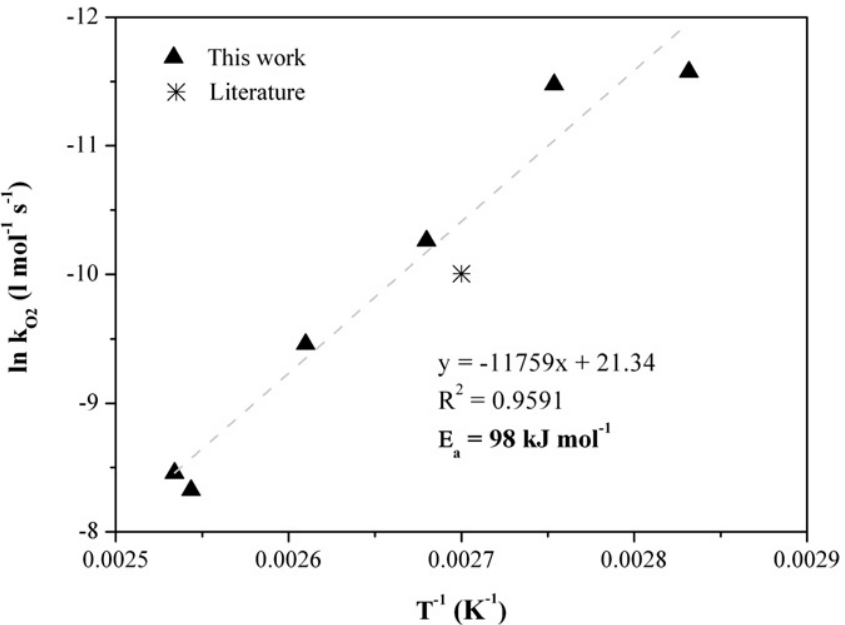

Fig. 9. Arrhenius plot of true second order rate constant $\left(k_{\mathrm{O}_{2}}\right)$.

\subsection{Identification of oxidation products}

In order to complete the identification of oxidation products, we have performed GPC analysis with UV detection at 276, 311 and $364 \mathrm{~nm}$ for the exposure at $110{ }^{\circ} \mathrm{C}$ under $3.0 \mathrm{MPa}$ oxygen pressure (Fig. 10). These results can be briefly resumed as follows. There are three distinct species or groups of species. $\mathrm{H}$ in the high molar mass range with a band centred at $20.6 \mathrm{~min}$, i.e. $\mathrm{M}_{\mathrm{w}} \sim 673 \mathrm{~g} \mathrm{~mol}^{-1}$. These species have an UV spectrum covering the three wavelengths investigated: 276, 311 and $364 \mathrm{~nm}$. In other words, they contain presumably the three major kinds of chromophores put in evidence by UV spectra. M at molar masses close to the initial stabiliser one, absorbing at $276 \mathrm{~nm}$ as AO4 but absorbing also at $311 \mathrm{~nm}$ where AO4 does not absorb or absorbs slightly. L at molar masses lower than the initial stabiliser one, having no absorption at $311 \mathrm{~nm}$ but absorbing at 276 and $364 \mathrm{~nm}$. Two components $\mathrm{L}_{1}$ and $\mathrm{L}_{2}$ can be in fact distinguished at low molar masses. $\mathrm{L}_{1}$ absorbs mainly at $276 \mathrm{~nm}$, more slightly at $364 \mathrm{~nm}$, and is eluted at $22.9 \mathrm{~min}\left(\sim 224 \mathrm{~g} \mathrm{~mol}^{-1}\right)$. $\mathrm{L}_{2}$ does not absorb at $276 \mathrm{~nm}$ but absorbs at $364 \mathrm{~nm}$ and is eluted at c.a. $23.5 \mathrm{~min}$, i.e. at a molar mass lower than $\mathrm{L}_{1}\left(\sim 168 \mathrm{~g} \mathrm{~mol}^{-1}\right)$. Products
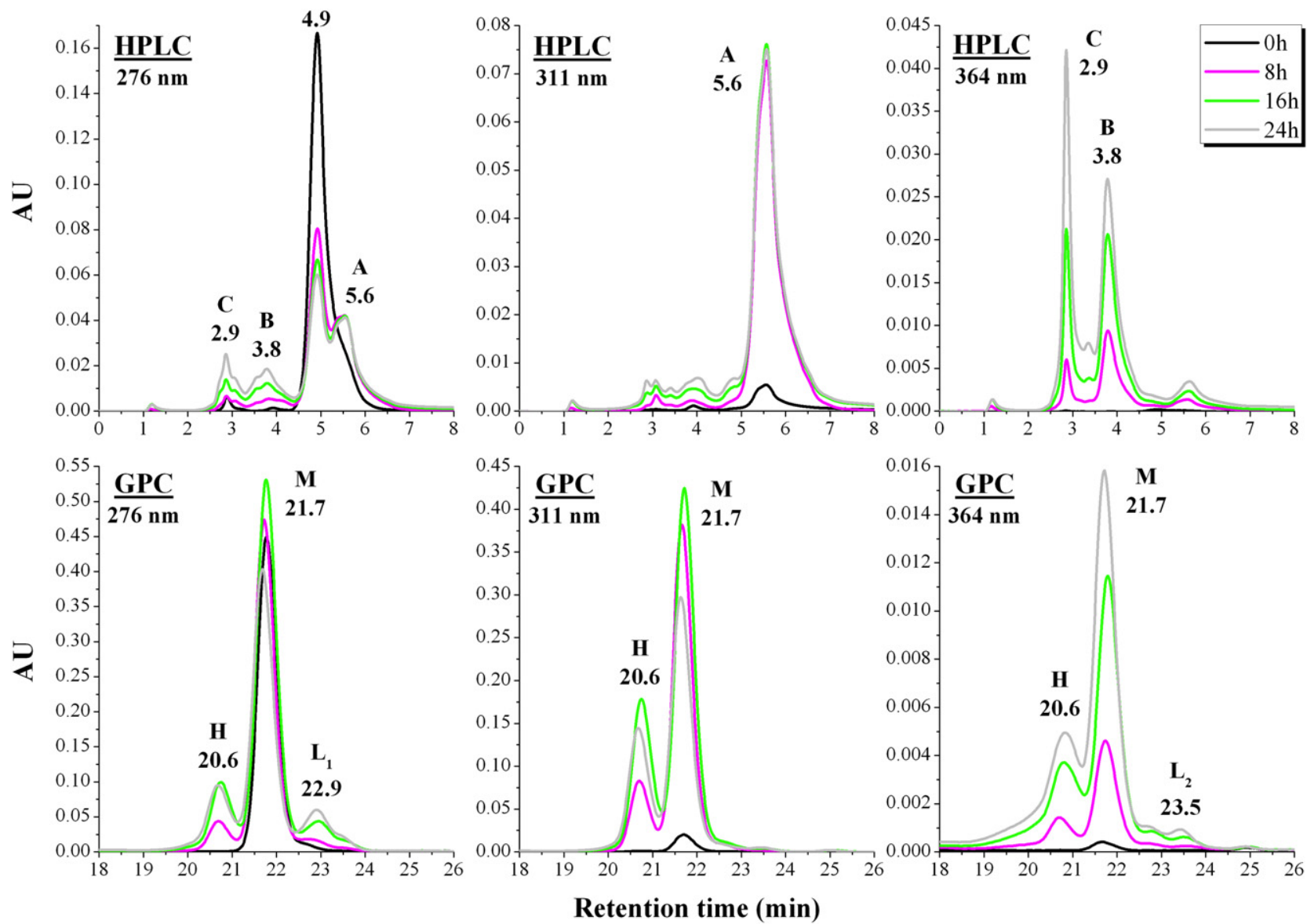

Fig. 10. Comparison of HPLC and GPC techniques applied to the aging process of the AO4 stabiliser at $110{ }^{\circ} \mathrm{C}$ under $3.0 \mathrm{MPa}$ oxygen pressure. 
Table 3

Summary of HPLC and GPC results.

\begin{tabular}{|c|c|c|c|c|c|c|}
\hline \multirow[t]{2}{*}{ Compound } & \multirow{2}{*}{$\begin{array}{l}\text { RT in } \\
\text { HPLC (min) }\end{array}$} & \multicolumn{3}{|c|}{ Absorbance } & \multirow{2}{*}{$\mathrm{M}_{\mathrm{w}}\left(\mathrm{g} \mathrm{mol}^{-1}\right)$} & \multirow{2}{*}{$\begin{array}{l}\text { Possible } \\
\text { attribution }\end{array}$} \\
\hline & & $276 \mathrm{~nm}$ & $311 \mathrm{~nm}$ & $364 \mathrm{~nm}$ & & \\
\hline $\mathrm{AO} 4$ & 4.9 & $\checkmark$ & & & 390.6 & $\mathrm{AO} 4$ \\
\hline A & 5.6 & $\checkmark$ & $\checkmark$ & & $\begin{array}{l}\sim 398(\mathrm{M}) \\
\sim 673(\mathrm{H})\end{array}$ & $\begin{array}{l}\mathrm{Ci} \\
\text { Dimer }\end{array}$ \\
\hline B & 3.8 & $\checkmark$ & & $\checkmark$ & $\begin{array}{l}\sim 168\left(\mathrm{~L}_{2}\right) \\
\sim 224\left(\mathrm{~L}_{1}\right) \\
\sim 398(\mathrm{M}) \\
\sim 673(\mathrm{H}) \\
\sim 168\left(\mathrm{~L}_{2}\right)\end{array}$ & $\begin{array}{l}\text { BQ, QM } \\
\mathrm{Ci} \\
\text { Dimer }\end{array}$ \\
\hline C & 2.9 & $\checkmark$ & & $\checkmark$ & $\begin{array}{l}\sim 224\left(\mathrm{~L}_{1}\right) \\
\sim 398(\mathrm{M}) \\
\sim 673(\mathrm{H})\end{array}$ & $\begin{array}{l}\text { BQ, QM } \\
\mathrm{Ci} \\
\text { Dimer }\end{array}$ \\
\hline D & 1.2 & $\checkmark$ & $\checkmark$ & $\checkmark$ & & \\
\hline
\end{tabular}

$\mathrm{H}$ result obviously from an oligomerisation, the predominant species being dimers. Products $\mathrm{M}$ are transformation products of $\mathrm{AO} 4$ but only with small mass molar changes. Products $L$ result presumably from the split-off of the aliphatic chain but, since they absorb UV, are constituted of the aromatic part or its transformation products. Table 3 shows a summary of results obtaining by both techniques and the possible attribution of transformation products found.

According to the literature $[15,16]$, the species L of low molar mass would be the benzoquinone (BQ) resulting presumably from the sequence of reactions shown in Scheme 1.

One cannot exclude an eventual rearrangement of the cyclohexadienone radical $\mathrm{CHL} \cdot$ by $\beta$ scission leading to a quinone methide (QM) (Scheme 2).

Whatever the nature of low molecular weight species (L), it must involve radical formation. Process IV-V of peroxide decomposition is a "reinitiation" generating two highly reactive radicals RO• and $\mathrm{R}_{1}$. Process VI generates also a highly reactive radical $\mathrm{R}_{2}{ }^{\bullet}$. Both $\mathrm{R}_{1} \bullet$ and $\mathrm{R}_{2} \bullet$ radicals can react with $\mathrm{O}_{2}$ generating $\mathrm{RO}_{2} \bullet$ radicals. All these processes tend to decrease the whole stabiliser efficiency.

The species having a molar mass very close to the initial stabiliser one $\left(\sim 398 \mathrm{~g} \mathrm{~mol}^{-1}\right)$ but with an UV absorption band bathochromically shifted from 276 to $311 \mathrm{~nm}$ could be a cinnamate

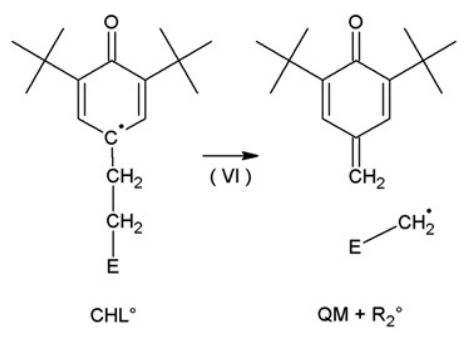

Scheme 2. Hypothetic mechanism for quinone methide formation.

(Ci) in which the hindered phenol function is restored [16]. There is no reason to suppose that this new phenol is not reactive towards oxygen (or peroxy radicals). Thus if cinnamate formation was an important secondary product of stabilisation processes, phenols belonging to the family of $\mathrm{AO} 4$, i.e. having a dimethylene unit in para position of the hydroxyl group, are expected to have a higher stabilising efficiency than the other phenols which do not benefit of this "recycling" of the phenolic group. The difference remains, however, to be experimentally checked.

Concerning now high molar mass species $(\mathrm{H})$, precise analytical studies have been previously published [11,15,17]. They reveal mainly the formation of various types of dimers and tetramers. Our results do not disagree with these interpretations. The most interesting fact appeared here in Fig. 10, is that the oligomers absorb as well at $276 \mathrm{~nm}$ as at 311 or $364 \mathrm{~nm}$. It can be deduced that the oligomers contain as well unreacted phenolic groups as cinnamate and/or more conjugated species.

\section{Conclusions}

The reaction between oxygen and an hindered phenol of the isooctyl-3-(3,5-di-tert-butyl-4-hydroxyphenyl)propionate (AO4) has been studied in an inert solvent (polydimethylsiloxane oil) at temperatures ranging from 80 to $120^{\circ} \mathrm{C}$. UV/VIS spectrophotometry, HPLC and GPC (with UV detection) have been used to characterize the reaction products.

The kinetic study of antioxidant consumption reveals a simple pseudo first order reaction whose rate constant values and activation energy have been determined. Kinetic parameters obtained in this study fit with the values calculated in our previous work [10] and the
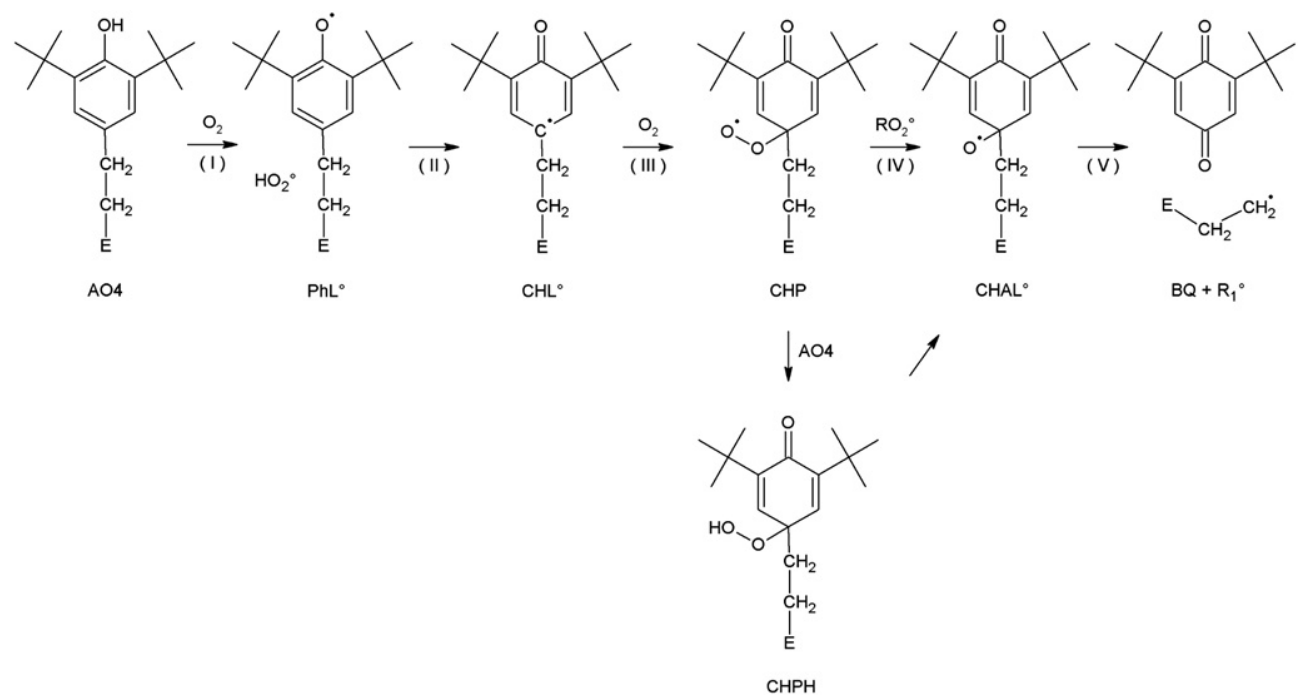

Scheme 1. Presumed pathway for benzoquinone formation ( $E=$ alkyl ester). 
ones found by other authors. If the reaction between oxygen and hydrocarbon substrates is negligible at moderate temperatures $\left(<200{ }^{\circ} \mathrm{C}\right)$ and oxygen pressures $(<10 \mathrm{MPa})$, this is not the case for phenolic stabilisers, owing to the very high radical reactivity of the phenol group linked to the low dissociation energy of the $\mathrm{O}-\mathrm{H}$ bond ( $\sim 340 \mathrm{~kJ} \mathrm{~mol}^{-1}$ against $\sim 390 \mathrm{~kJ} \mathrm{~mol}^{-1}$ for a saturated hydrocarbon).

We have tried to identify the oxidation products which are expected to be at least partly the same as in polymer stabilisation processes. Three groups of products differing by their average molar mass have been observed. Products of molar mass lower than the starting stabiliser (AO4) result from splitting-off the aliphatic tail of the molecule. The predominant UV absorbing species would be a benzoquinone $\left(M_{\mathrm{w}}=220 \mathrm{~g} \mathrm{~mol}^{-1}\right.$ against $\sim 224 \mathrm{~g} \mathrm{~mol}^{-1}$ according to GPC) or a quinone methide.

The cinnamate $(\mathrm{Ci})$ parent of the starting stabiliser seems to be formed with a relatively high yield. It results from a sequence of rearrangements only possible in substituted alkyl propionates or phenols having a polymethylene sequence in para position relatively to the $\mathrm{OH}$ group. This property is interesting because it regenerates a phenol group able, in principle, to participate to a further stabilisation event.

Products of molar mass higher than the antioxidant one were formed at a non negligible yield. They are presumably oligomers with a clear predominance of dimers $\left(M_{\mathrm{w}} \approx 673 \mathrm{~g} \mathrm{~mol}^{-1}\right.$ according to GPC).

Reactions leading to low molar mass products are expected to generate new radicals able to initiate oxidation chains. In other words, they are expected to lower the stabiliser efficiency.

In contrast, the reaction responsible for cinnamate formation, which regenerates the phenolic function, is expected to increase the stabiliser efficiency. The balance between all these processes must depend of oxygen pressure and stabiliser concentration. A systematic study of these factors is under progress in our laboratory.

\section{Acknowledgements}

Financial support for this investigation has been provided by the Spanish Ministerio de Ciencia e Innovación through the "Ayudas de estancias de movilidad posdoctoral en el extranjero" Program.

\section{References}

[1] Bolland JL, Gee G. Kinetic studies in the chemistry of rubber and related materials II. The kinetics of oxidation of unconjugated olefins. Trans Faraday Soc 1946;42:236-43.

[2] Bolland JL, Gee G. Kinetic studies in the chemistry of rubber and related materials III. Thermochemistry and mechanisms of olefins oxidation. Trans Faraday Soc 1946:42:244-52.

[3] Bolland JL, Ten Have P. Kinetic studies in the chemistry of rubber and related materials V. The inhibitory effect of phenolic compounds on the thermal oxidation of ethyl linoleate. Discuss Faraday Soc 1947;2:252-60.

[4] Richaud E, Farcas F, Fayolle B, Audouin L, Verdu J. Accelerated ageing of polypropylene stabilized by phenolic antioxidants under high oxygen pressure. J Appl Polym Sci 2008;110:3313-21.

[5] Zhu Q, Zhang XM, Fry AJ. Bond dissociation energies of antioxidants. Polym Degrad Stab 1997;57:43-50.

[6] Denisov ET. A new semiempirical method of estimation of activity and bond dissociation energies of antioxidants. Polym Degrad Stab 1995;49:71-5.

[7] Boersma A. Predicting the efficiency of antioxidants in polymers. Polym Degrad Stab 2006;91:472-8.

[8] Zeynalov EB, Allen NS. Modelling light stabilizers as thermal antioxidants. Polym Degrad Stab 2006;91:3390-6.

[9] Coquillat M, Verdu J, Colin X, Audouin L, Celina M. A kinetic evaluation of the thermal oxidation of a phenol stabilised polybutadiene. Polym Degrad Stab 2008;93:1689-94.

[10] Navarro R, Audouin L, Verdu J. Reactions of antioxidants with molecular oxygen. Part I. 2,2'-methylene-bis(4-methyl-6-tert-butylphenol) in silicone matrix. Polym Degrad Stab 2011;96:220-5.

[11] Pospíšil J, Habicher WD, Pilař J, Nešpůrek S, Kuthan J, Piringer GO, et al Discoloration of polymers by phenolic antioxidants. Polym Degrad Stab 2002; 77:531-8.

[12] Scheirs J, Pospíšil J, O’Connor MJ, Bigger SW. Polymer durability: degradation, stabilization, and lifetime prediction. In: Clough RL, Billingham NC, Gillen KT, editors. Advances in chemistry series, vol. 249. Washington: American Chemical Society; 1996. p. 359-74.

[13] Shanina EL, Belyakov VA, Zaikov GE. Phenol antioxidant consumption rate in polypropylene. Polym Degrad Stab 1990;27:309-17.

[14] Van Krevelen DW, Hoftyzer PJ. Properties of polymers. Amsterdam: Elsevier; 1976. pp. 403-425 [chapter 18].

[15] Klemchuk PP, Horng PL. Transformation products of hindered phenolic antioxidants and colour development in polyolefins. Polym Degrad Stab 1991; 34:333-46.

[16] Pospíšil J, Nešpůrek $S$, Zweifel H. The role of quinone methides in thermostabilization of hydrocarbon polymers. I. Formation and reactivity of quinone methides. Polym Degrad Stab 1996;54:7-14.

[17] Allen DW, Clench MR, Crowson A, Leathard DA. Characterisation of solventextractable transformation products of high molecular weight hindered phenols in polypropylene subjected to ionising radiation in air or to thermal ageing. Polym Degrad Stab 1993;39:293-7. 